\title{
A systematic review of predictive models for recurrence and mortality in patients with tongue cancer
}

\section{Almangush, Alhadi}

2020-03

Almangush , A, Coletta , R D , Nieminen , P , Kowalski , L P , Leivo , I \& Salo , T 2020 , ' A systematic review of predictive models for recurrence and mortality in patients with tongue cancer ' , European Journal of Cancer Care , vol. 29 , no. 2 , 13211 . https://doi.org/10.1111/ecc.13211

http://hdl.handle.net/10138/328269

https://doi.org/10.1111/ecc.13211

unspecified

acceptedVersion

Downloaded from Helda, University of Helsinki institutional repository.

This is an electronic reprint of the original article.

This reprint may differ from the original in pagination and typographic detail.

Please cite the original version. 


\section{Letters to the Editor}

Comment on

\section{A systematic review of predictive models for recurrence and mortality in patients with tongue cancer}

\section{Sir,}

We have read with interest the recent systematic review by Palazon-Bru et al. that focused on predictive models for tongue cancer (Palazon-Bru et al., 2019). Although we agree with some of the criticisms raised regarding the BD model (Almangush et al., 2015), such as the retrospective nature of our cohort, we would like to explain that many aspects criticized in the review are irrelevant. The authors of this review stated that the BD study did not provide information about the use of chemotherapy as a treatment option (Palazon-Bru et al., 2019). It is important to note that our study included only patients with early-stage (cT1-T2N0) oral tongue squamous cell carcinoma (OTSCC), and for such cases, the primary treatment is surgery, whereas chemotherapy is not usually recommended.

Palazon-Bru et al. have mentioned that "the histological confirmation criteria may have varied over 30 years." We emphasize that the histological assessment was carried out by an observer (A.A.) and reviewed by an experienced pathologist (I.L.), and both were blinded regarding clinical information. This has been clearly explained in our study which indicated that the histological assessment was conducted at the same period. The authors of the review have also criticized that "the histopathological parameters of the Almangush models are uncommon in clinical practice." It is necessary to underline that our model includes depth of invasion, which is routinely reported in daily practice, and tumour budding, which is becoming widely recognized by pathologists as it has been officially included as an additional prognostic marker for colorectal cancer (O’Sullivan et al., 2015, Zlobec \& Lugli, 2018). 
Regarding sample size, the authors (Palazon-Bru et al., 2019) mentioned that the BD study has developed models "always using 10 candidate predictors, which represents the EPV less than 10." In our study, however, the 10 mentioned variables were clearly entitled as unadjusted univariate analyses (Almangush et al., 2015). We have also clearly stated in the statistical methods that "Multivariate analysis was performed to evaluate the independent prognostic strength of BD scores when adjusted to other clinicopathological covariates (age, gender, tumour stage, and tumour grade) and worst pattern of invasion."

The authors (Palazon-Bru et al., 2019) also stated that the BD study should have analysed the site of the tumour. We emphasize that our study included only oral tongue cancers, and this was clearly indicated in our article (Almangush et al., 2015).

\section{References}

Almangush A, Coletta RD, Bello IO, Bitu C, Keski-Santti H, Makinen LK, Kauppila JH, Pukkila M, Hagstrom J, Laranne J, Tommola S, Soini Y, Kosma VM, Koivunen P, Kowalski LP, Nieminen P, Grenman R, Leivo I and Salo T (2015). A simple novel prognostic model for early stage oral tongue cancer. Int J Oral Maxillofac Surg 44: 143-50.

O'Sullivan B, Brierley JD, D'Cruz AK, Fey MF, Pollock R, Vermorken JB and Huang SH (2015). UICC Manual of Clinical Oncology, Ninth Edition. Published 2015 by John Wiley \& Sons, Ltd.

Palazon-Bru A, Mares-Garcia E, Lopez-Bru D, Mares-Arambul E, Gil-Guillen VF and Carbonell-Torregrosa MA (2019). A systematic review of predictive models for recurrence and mortality in patients with tongue cancer. Eur J Cancer Care (Engl): e13157.

Zlobec I and Lugli A (2018). Tumour budding in colorectal cancer: molecular rationale for clinical translation. Nat Rev Cancer 18: 203-204. 